\title{
USING CONTRACTS IN GROUPWORK
}

\section{MICHAEL PRESTON-SHOOT}

Although regularly mentioned in the groupwork literature, contracts, as a working concept, have rarely been elaborated or explored. Yet, as research into the effectiveness of social work demonstrates, contracts form part of an identifiable, successful approach to work, which has user involvement as a central theme. This paper outlines the basics of this approach and then examines the special features of groupwork as they affect the process of using contracts. The paper concludes with suggestions regarding the framework and content for working agreements with service users which are seen as morally binding on the participants.

Several key ingredients of successful work are:

i. problem cornering: where problems are well-defined, broad aims are sub-divided into more specific objectives and further into tasks, small and precise enough to be managed quickly;

ii. tasks are discussed, agreed and provide a clear focus;

iii. significant people in the worker-user environment give active support;

iv. reviews are held regularly to ensure work retains a clarity of purpose;

v. differences between workers and users are openly acknowledged;

vi. users' problem definitions are taken seriously; users are encouraged to contribute actively to decision-making and to the work;

vii. users' rights to information, to access to records, and to complaints procedures are emphasized;

viii. worker-user intentions are compatible, goals are agreed and the encounter is contractual (Stein and Gambrill, 1977; Mullender and Ward, 1985; Preston-Shoot, 1985; Sheldon, 1986; Corden and Preston-Shoot, 1987).

Contracts, therefore, form part of an approach which encourages user involvement and commitment, and aims to promote an understanding of rights and an acceptance of responsibilities by all parties. Expectations, objectives and the methods of achieving tasks are negotiated openly. Contracts also provide a basis for subsequent review, for assessing progress both of the content of the work and the worker- 
user relationship underpinning it, for evaluation and, if necessary, redefining the goals for or structure of the work.

The concept of contract is frequently mentioned in groupwork texts as essential to informed consent to join and to the successful achievement of the group's objectives. However, it is rarely explored. This paper explores the special features of groupwork as they affect the process of negotiating contracts, and the practice implications of the issues identified.

\section{Whose needs? Whose objectives?}

A common assumption is that contracts and groups require mutuality: agreed upon goals (Maluccio and Marlow, 1974). However, mutual agreement is neither necessary nor a guarantee of purposeful activity and successful outcomes. It may be contra-indicated in terms of the time and encrgy spent achieving it (Macarov, 1974). More likely, contracts will contain elements of mutuality and of reciprocal exchange. Indeed, where workers and users hold different objectives, contracts are a means of respecting each participant's expressed needs. The major requirement, therefore, is that agreements contain goals which the participants are willing and the resources to tackle (Corden and Preston-Shoot, 1987; Preston-Shoot and Williams, 1987), and comprise an agreed agenda of work together. This agenda may be based either on a consensus and/or co-operation in helping participants achieve their respective goals. Contracts involving reciprocal exchange, where the parties acknowledge that agendas may not be identical but agree to work on each other's goals, require agreement on what the group is for, how it will proceed, and the rights and duties of the participants.

In some groups, for example with prospective foster parents, social workers will determine the goals in advance, these objectives being strongly influenced by agency function. Prospective members are informed what will happen and the proposed programme is discussed with them, so that they can decide whether to contract in.

In some other groups, members will determine the objectives. Here the groupworker's role is to help members reclaim some degree of control over their lives by identifying their concerns and targets for change, setting an agenda and implementing action (Mullender and Ward, 1985).

Most groups fall somewhere between these two approaches, and negotiating objectives can seem a complex process. The needs which workers and users identify may differ, as may how they are understood. Prospective members may doubt the usefulness of groups or disagree among themselves about the group's aims or priorities. 
Several practice implications arise from this discussion. First, acknowledging the significance of their experience, and involving potential users in determining their own needs and deciding action, is a value and practice shift which may be unfamiliar to people accustomed to being regarded as passive recipients. Since many users are amongst the most disadvantaged members of society, considerable time and effort may be required to combat their feelings of powerlessness, isolation and hopelessness, and the scepticism with which they may greet social workers. Groupworkers, to achieve this value and practice shift, may need to communicate their understanding of organisational and structural inequalities as well as what groups can achieve. Moreover, enabling users to identify what kind of groupwork is appropriate for them and integrating their suggestions is likely to promote attendance and confidence in their strengths.

Secondly, distinguishing between aims, objectives and indicators, and being clear what is expected, is important (Preston-Shoot and Williams, 1987). Realistic, specific objectives, together with indicators by which to judge movement towards them, will give everyone a clear basis for making suggestions, for contracting in and finding a relevant way of working. Lack of clarity may result in confusion and dissatisfactions. Vague objectives make evaluation of the results of the contract and group difficult. Agreements, therefore, should be framed in terms of the current and desired situation, the intervention or type of work suggested by the desired situation, indicators to assess progress, and how progress will be recorded (Preston-Shoot, 1988).

Thirdly, groupworkers must allow adequate time for inviting potential members to join the group, and for the group's formation; for introducing themselves and their ideas; and seeking to understand members' objectives. The end goal in this process, the contract, requires the groupworker to give accurate information about the possibilities for the group, to describe what membership might entail, to disclose any constraints on what they can agree to (agency policy, statutory duties) and to discuss any concerns or anxieties which prospective members might hold.

When the group convenes and members consider that they can work together productively within an agreement on what needs to be attempted, a mainstream group contract can be devised, supplemented if necessary by individual contracts. Where informed agreement is absent, either because of divergent views about the work to be attempted or because the time available to reach agreement has been insufficient, a preliminary group contract will be necessary. This is an agreement to assess if there is a basis for further work together once 
each person's views, and the similarities or differences between them, have been further elicited and explored. Some specific goals, where these can be agreed, may be pursued at the same time.

Various proformas and exercises are useful in enabling potential users to share responsibility for defining goals, to make informed decisions about participating and to identify the experience and knowledge they bring:

i. a leaflet in which groupworkers describe the group they envisage and why they believe it will be helpful;

ii. a brainstorm where members describe their images of social workers and of groups;

iii. a brainstorm where members describe their ideal group. Having identified what their ideal group would look like, members can be asked for their original hopes and objectives. This process concludes with a consideration of how the 'original' and the 'ideal' might be connected. Identifying the 'ideal' helps to liberate members from the constraints of day-to-day reality;

iv. sentence completion, to answer what members want, can offer, hope and fear in relation to a group. For instance:

what I want to know before agreeing to join is ...

I agreed to come to this group because ...

what I want from attending this group is ...

my expectations about this group are ...

my hopes/fears about this group are. . .

what I am most anxious about in groups is ...

what I am most anxious about in this group is ...

previous groups I have been in were ...

what I enjoyed most about these was...

what I disliked about these was ...

what I found most useful in these groups was...

things I can offer this group are...

my strengths/weaknesses are ...

when with social workers I feel ...;

v. members identify a situation or problem which concerns them. The group can then share in devising a proposal. Working together in this way can be productive and enjoyable. Members will gain in confidence as they work on what this proposed group might do, why it might do it, how and with what target in view;

vi. members give their reasons for coming. The group then works on choosing the most important as a basis for an agreement about the work, about individual and group objectives. 


\section{Individual and/or group needs and objectives?}

Most groups contain elements of both, the balance depending on the type of group. A social action group, working for external change, will require a contract with the group. Individual needs will be less in focus but the group contract will include what individual members agree to do. In contrast, a therapy group may emphasise both group and individual objectives. Contracts will be drawn up for the group and for individual members. These examples illustrate that, sometimes, individual objectives may fall outside the objectives for particular groups, and that group objectives may be more than the sum of individual objectives.

Contracts are designed to respect expressed needs. Problems may arise, therefore, if a contract with one individual appears to conflict or be incompatible with an agreement with another member or with the group. Here the group must resolve how much difference it can tolerate. This issue demonstrates the importance of negotiating a collective agreement about the group's purpose and structure, together with contracts with individual members about their objectives from group membership, where this appears indicated.

There are available four sets of agreements: worker-group, worker-member, member-group, and member-member. Worker-group and member-group agreements will cover the group's purposes, together with how the group will work and each person's tasks or responsibilities. Worker-member and member-member agreements will focus on how individuals will use the group, their hopes and fears, and on their individual expectations, commitments, purposes and tasks within the collective agreement. Member-member and member-group agreements may also include what they are offering each other. Thus, the process of contracting involves not only discussion about task and goals, but also negotiations about procedures and structure: what kind of group this is; what patterns of interaction are sought; how the group will do things; how people will treat each other. Making and revising contracts, therefore, centres around group process, interpersonal interaction and exchange, as well as tasks.

Objectives and tasks, whether individual or group, should describe what people will do, behaviourally, and be realistic and achievable (Preston-Shoot and Williams, 1987).

\section{Attachments to other systems. Significant other people}

Any group's effectiveness will depend on the attitudes and co-operation of people outside it: colleagues, families, peers. Accordingly, the concept 
of secondary contracts assumes importance.

Competing needs and priorities within an organisation, and the attitudes of colleagues, can frustrate a group. The practice implication here is that groupworkers must negotiate time, workload space and resources with their colleagues, and obtain the necessary support. Producing a proposal and inviting comment is probably necessary before securing permissions (Preston-Shoot, 1987).

Once groups have identified their objectives, an important next step is to secure the co-operation of those whose involvement in the change process is crucial to the achievement of the identified goals. Using contracts can have a major value here in securing the involvement and resources of professionals, carers and other 'action systems.' This may be done individually or in a case conference format where group members and these significant other people meet to negotiate an agreement.

Competing demands and priorities within family and peer groups may also impinge on a group. Their reactions must be considered and addressed, otherwise their anxiety, resentment or pressure may sabotage an individual's group membership. Increasingly, in children's groups, groupworkers are actively involving parents and teachers in the group's process: contributing their concerns; defining objectives; reviewing progress. Explaining to family members the group's purpose, structure and objectives, together with what is required for effective membership, such as regular attendance and confidentiality, is an important practice task.

Where peer groups impinge on group members, the group's programme should include how members and the group will respond to attitudes that are encountered and to any sense of widening separation and differences which membership may create.

\section{Group stages}

Groups negotiate stages. These have been variously conceptualised (Tuckman, 1965; Heap, 1977; Preston-Shoot, 1987). To ignore the processes involved in the stages may mean that groupworkers respond inappropriately. For example, groups are often too short to allow adequate time to be given to the work agreed, to consolidating progress, or to termination. Often, the number of sessions seems unrelated to the problems defined, the goals set or the progress made. The significance of this for using contracts in groupwork is threefold.

First, whilst the emphasis of a contractual approach is on explicitness, on clear objectives, some groups may experience practical limit- 
ations to this initially. Clarity may become possible only with time, perhaps because participants are wary of openly specifying their expectations, needs or ideas immediately. Then, rather than a mainstream agreement covering the main features of the work, early sessions may require a preliminary contract whilst participants, without committing themselves fully to the group, explore what each brings and compare the reality of membership with earlier expectations. An early review, concluding the opening sessions with negotiating full membership and a mainstream contract, recognises this stage of forming/joining. This acknowledges that the right to decline, and the feasibility of working together, may only be truly available once participants have experienced what to expect from group membership.

Secondly, contracts must not be rigid but rather reflect the unfolding and developing nature of the group. To assume that no further consideration is required once an initial agreement has been concluded is a mistake. Goals must be appropriate to the stage and development of the group. What is required, therefore, is either one agreement that builds in the necessary flexibility, or a series of reviews and renegotiations. This, too, suggests that groupworkers must be realistic about the number of sessions planned.

Thirdly, the stages emphasise the crucial importance of reviews, the format for which has been described elsewhere (Corden and Preston-Shoot, 1987; Preston-Shoot, 1988). Initially groups are often concerned with inclusion issues - who is in - and with control issues - how much influence members have got. Setting norms may follow, including what members feel they may do and say. If groups work well, members increasingly assume responsibility for both the task and maintenance needs of the group, groupworkers becoming less central (Heap, 1977). As groups develop, initial objectives will be accomplished or will require modification. Some goals may prove to be unrealistic. Revision may be necessary to address reasons why objectives are being missed. Equally, as participants work together, various defences or behaviours may arise from the task of or dynamic interactions in the group: As termination approaches, groups may be characterised by denial, anger, regression or evaluation. These are examples of groups as developing phenomena, and of the importance, therefore, of reviews as opportunities to examine both process and the outcome of the group's work towards objectives. Then, on the basis of any dissatisfactions, the group's structure or goals may be revised. However, reviews must be carefully timed because what the stages also highlight is the depth of feeling that can be present in groups, such that it will not be possible for the group always to remain within the terms of the contract. Group- 
workers will need to be sensitive to when flexibility beyond the agreement is necessary because of the stage of the group.

\section{Task versus maintenance needs}

Thus far, considerable emphasis has been given to specifying goals and tasks, that is to defining the group's work. Also required is an emphasis on those behaviours necessary to maintain the group and its members. Groups can easily ignore these maintenance issues. The group's work will affect each member and, as child abuse teams will testify, the emphasis on getting procedures right and completing tasks can result in the effect of the work on members being overlooked or underplayed.

A balance must be achieved between task needs, and individual and group maintenance needs. The latter requires that groupworkers identify feelings about group membership, make connections between people and support members through the work. Task and relationship are inseparable. The importance of being explicit and goal oriented should not mean that less tangible elements, like the experience of membership, are ignored. If this balance is lost, the contractual approach may become yet another means of 'doing to' users rather than 'working with.' The process of negotiation calls for sensitivity and responsiveness. Rational and sensible contracts will break down if the underlying processes in the relationships which are forming are ignored. Put another way, effective contracts emanate not only from agreement about the tasks but also from an understanding of attachments and from concentration on the developing user-worker relationship (Skidmore, 1988).

\section{Power}

Social workers wield considerable power and authority derived from legislation, training, agency position, knowledge and practice experience. This power imbalance affects negotiations and influences events. For example, users present problems which fit the perceived interests or purposes of workers. Thus, how much influence will potential group members have when groupworkers are more practised in managing negotiations and more knowledgeable about available resources and potential possibilities? Can contracts modify the power imbalance?

Contracts will not eliminate inequality but will modify the power equation. Even where statute limits users' rights and the freedom of social workers, contracts will identify the extent of their freedom and power. Moreover, a contractual approach increases user participation in 
negotiations about decisions that affect their lives, for instance what groupwork is appropriate. Users have commented that contracts, and the consumer involvement movement of which they form a part, are evidence of an openness and honesty which reduces suspicion and mistrust, and creates a healthier work environment (Smith and Corden, 1981; Preston-Shoot, 1985). Contracts provide specific information and indicate what has to be done, rather than an illusion of control and no indication of how participants can intervene to their advantage (Stein and Gambrill, 1977).

Groupworkers can demonstrate a wish to modify the power imbalance by acknowledging the inequality and discussing both the type of authority members perceive them as having and that which groupworkers wish to exercise. Providing a personal profile and an outline of their reasons for wishing to be involved with the group also helps (Preston-Shoot, 1987). Furthermore, groupworkers can elicit any concerns members may have about membership and suggest an open structure for the group: access to records, involvement in recording, feedback to workers in reviews. These approaches enable members to participate actively in devising and running the group, and to make an informed choice about membership.

Some of the ideas presented above provide safeguards for users and a structure, therefore, for modifying the power imbalance. This is not to underestimate the power imbalance but to take account of it and of the constraints under which group members live because of continuing inequalities in society. The emphasis is on negotiation not compulsion, on respecting users' views, not imposing problem definitions. Possible pressures to comply (worker status, statutory orders, fear of loss of goodwill or services) are explored to ensure that contracts are not agreed because of undue influence. Outlining what groupworkers agree to do recognises that they are accountable for their commitments and that outcome or failure is not solely dependent on or the responsibility of the group's members.

The final safeguard is to determine the procedures in the event of breakdown or non-fulfilment: what members and groupworkers can do if either fail to honour their agreements. In planning the group, 'what if ...' questions should be answered (what if non-attendance? what if a member commits further offences?). This will provide some guidance in respect of breakdown. Non-fulfilment by one party can release the other party from their part in the agreement, if they choose to exercise that option. Other options include convening a review to discuss the difficulties and/or giving users access to a complaints procedure, to the groupworker's supervisor or, where one exists, funding committee. 


\section{Framework and substance}

Contracts, preferably written to minimise any possibility of misunderstanding, can be divided into framework - the structure for the group and substance - the content of the work. The common elements of framework, which should be included in all agreements, include:

i. statements about confidentiality, its boundaries, and minimum requirements for the work, such as regular attendance;

ii. group rules: time keeping, participation, methods of control, methods of changing the rules;

iii. frequency and number of sessions;

iv. necessary resources;

v. what records will be kept, the uses to which they will be put, who will contribute to them and how, who will have access to them;

vi. what recourse participants have if individuals fail to honour their agreements;

vii. the process for altering the agreement, normally a request for a review;

viii. the purpose, structure and frequency of reviews, for instance who will chair these, records kept, how the agenda will be set.

Framework elements which may be added, if relevant to the type of group, include:

i. rules about contact between members or with the groupworker between sessions;

ii. statements about why members were referred or are meeting together or have requested the groupworker's assistance.

The common elements of substance include:

i. the current situation which inspired the group;

ii. the desired situation to which the group aspires, including a statement of aims, objectives and targets for change;

iii. the methods to be used to move towards the desired situation;

iv. the tasks and responsibilities which members and groupworkers agree to undertake;

v. how progress will be assessed.

This part of the contract may also include statements relating to the desired situation to which individuals aspire, that is their objectives for 
group membership, and to the groupworker's expectations of members and members' expectations of each other and of the groupworker. This paper has emphasised throughout that contracts must contain statements regarding the groupworker's commitments, not just what users agree to undertake. Contracts are often deficient in this respect. A contract does not exist unless both parties have clearly specified duties and responsibilities that are not already required by law.

\section{Conclusion}

Even if groupworkers do not use explicit contracts, the framework presented here will guide them through their interactions with prospective members. However, explicit working agreements, seen as morally binding, do promote participation and commitment, besides clarifying expectations and focus. They are a response to calls for ensuring standards of practice and involving users in shaping practice; for sharing power, rights and responsibilities. They aim both to minimise confusion and a retreat by users into a numbed and passive acceptance, and also to make social workers explicit about their interventions. In particular, they require social workers to answer how, in respect of each piece of work, they resolve the possible practice dilemmas of care versus control, partnership versus professionalism, and rights versus risks. Contracts, therefore, provide opportunities for groupworkers and members alike.

\section{References}

Corden, J. and Preston-Shoot, M. (1987) Contracts In Social Work. Aldershot: Gower.

Heap, K. (1977) Group Theory for Social Workers. London: Pergamon. Macarov, D. (1974) 'Client-worker agreement: necessity, desideratum or dogma?', Social Work Today, 4(24), pp. 773-76.

Maluccio, A. and Marlow, W. (1974) 'The case for contract'. Social Work (USA), 19(1), pp. 28-36.

Mullender, A. and Ward, D. (1985) 'Towards an alternative model of social groupwork', British fournal of Social Work, 15(2), pp. 155-72.

Preston-Shoot, M. (1985) 'An evaluation of a policy of family involvement in one FSU from the families' perspective', FSU Quarterly, 36, pp. 52-64.

Preston-Shoot, M. (1987) Effective Groupwork. London: Macmillan.

Preston-Shoot, M. (1988) 'A model for evaluating groupwork', Groupwork, 1(2), pp. 147-57. 
Preston-Shoot, M. and Williams, J. (1987) 'Evaluating the effectiveness of practice', Practice, 1(4), pp. 393-405.

Sheldon, B. (1986) 'Social work effectiveness experiments: review and implications', British fournal Of Social Work, 16(2), pp. 223-42.

Skidmore, D. (1988) 'Attachment theory and the work of the probation officer', Practice, 2(1), pp. 31-46.

Smith, G. and Corden, J. (1981) 'The introduction of contracts in a Family Service Unit', British fournal Of Social Work, 11(3), pp. 289314.

Stein, J. and Gambrill, E. (1977) 'Facilitating decision making in foster care', Social Service Review, 51, pp. 502-11.

Tuckman, B. (1965) 'Developmental sequences in small groups', Psychological Bulletin, 63, pp. 384-99. 